\title{
Anatomy of the Gallbladder Venous System - a Corrosion Compounds Study
}

\author{
CĂLIN MOLNAR ${ }^{1}$, IOANA HĂLMACIU ${ }^{2 *}$, ADRIAN TUDOR ${ }^{1,2}$, BOGDAN ANDREI SUCIU ${ }^{1,2}$, \\ ZOLTAN PAVAI ${ }^{2}$, ZSUZSANNA PAP ${ }^{2}$, KLARA BRÎNZANIUC ${ }^{2}$, VLAD BUTIURCA ${ }^{1}$, \\ MARIAN BOTONCEA ${ }^{1}$, COSMIN NICOLESCU ${ }^{1,2}$ \\ ${ }^{1}$ Surgical Clinic No. 1., Tîrgu-Mureș Emergency County Hospital, University of Medicine, Pharmacy, Science and \\ Technology George Emil Palade, 38 Gh. Marinescu Str., 540139, Tîrgu-Mureș, Romania \\ ${ }^{2}$ University of Medicine, Pharmacy, Science and Technology George Emil Palade, Anatomy Department, 38 Gh. \\ Marinescu Str., 540139, Tîrgu-Mureș, Romania
}

\begin{abstract}
Although it has long been considered that the gallbladder lacks a constant venous vascularization the existence of multiple surgical complications has required various studies to elucidate this hypothesis.
\end{abstract}

Keywords: gallbladder, veins, corrosion

Classically there are several hypotheses according to which the venous component, apparently absent, is materialized by the existence of various venous branches that form at the neck of the gallbladder approximately 1 to 5 of them forming a venous plexus or drain directly in the right branch of the portal vein. Most anatomical descriptions use this venous drainage as a constant. There is also an anatomical component called posterior, responsible for collecting the venous blood from the body and bottom of the gall bladder, which is described as being collected directly in the port system of the segment V and / or IVB following Couinaud's segmentation. The vast majority of these descriptions come from classical imaging studies obtained by in-vivo injection of the various intraoperative dyes or most commonly by computed tomography angiography (CTA) or magnetic resonance angiography (MRA) [1,2]. The use of plastic materials in human medicine has become more popular in recent years. Currently, plastic materials are frequently used in human anatomy teaching techniques, experimental studies, and in various reconstructive surgical techniques $[3,4]$. Our study aims to highlight the gallbladder veins through the direct study of the pieces of hepatic corrosion and the classification of these data.

\section{Experimental part}

The biological material used in this paper is represented by a batch of 50 pieces of liver corrosion, respectively 10 hepatic pieces fixed in formaldehyde. The liver parts came from the prosecution service of the Morphopathology Department and from the Anatomy and Embryology Department of the University of Medicine, Pharmacy Science and Technology George Emil Palade of Tîrgu Mureș. The study was conducted with the approval of the Scientific Research Ethics Committee of the University and was based on a collaboration protocol between the two beforementioned departments.

All corrosion parts have been processed according to a predetermined protocol, which comprises of distinct stages. After processing the pieces were photographed and biological parameters of practical importance were determined, the results were then added to a database created using Microsoft Excel software and were subsequently interpreted statistically.

The hepatic anatomical pieces were fixed in 5-29\% formaldehyde dissected and photographed. Particular interest was given to vessel caliber and number. The results were compared and added to those obtained from the corrosion batch.

Corrosion preparations were carried out by successively performing 5 stages: dissection stage, corrosion stage, injection stage, forced polymerization stage, corrosion stage and hydro dissection stage, based on the previous experience of the Anatomy Department within the University of Medicine and Pharmacy in Timisoara, Romania.

a.Dissection stage: During this stage, the native part is subjected to a process of washing with distilled water to remove constituted thrombi. After this stage, a thorough dissection of the related vascular elements is made with the identification of the right and left hepatic artery. Accessory hepatic arteries were also identified in this stage. After identification, dissection and possibly distinct cannulation of these atypical vascular elements, we proceed to dissection and cannulation of the classical elements of the hepato-duodenal ligament: the right and left branches of the proper hepatic artery, the portal vein main trunk, the common bile duct (CBD) and last but not least the inferior vena cava (IVC) that can be cannulated separately for the study of the trunk of the hepatic veins (HV). An important and mandatory detail of the corrosion process is the construction of a skeleton that physically supports the corrosion piece. 
This skeleton is made by injecting either the portal vein and its branches or by injecting the vena cava inferior and implicitly, retrograde hepatic veins. The amount of polymer required to make this skeleton is $80-100 \mathrm{ml}$. In our study we used portal vein injection to create the supporting skeleton. After mandatory identification of the vascular elements and of the accessory sources the plastic material preparation stage begins.

b.Corrosion stage: this stage begins with polymer preparation, in our case methyl methacrylate, commercially known as TECHNOVIT 7143, produced by HERAEUS ${ }^{\circledR}$ in a variety of colors. We used the following colors: blue, red, green and yellow. In some cases, we also used colors composed by mixing the above-mentioned main colors. The preparation of the resin for injection is done by mixing the polymer powder with the photosensitive solvent. Different percentages are used but frequently a ratio of $1 / 2$ to $1 / 3$ polymerizable powder material and the remaining Technovit 7143 universal solvent.

c.Injection stage: after the polymer is prepared in the required color and quantity, $80-100 \mathrm{ml}$ are used for the venous port and inferior cava system, 30-40 ml for the biliary system and $40-50 \mathrm{ml}$ for the hepatic arterial system. The actual injection of polymer is carried out with the piece submerged in a liquid bath $\left(40^{\circ} \mathrm{C}\right.$ hot water) in an adequate container. The specimen is suspended by the coronary and triangular ligaments. Polymer injection is carried out in the venous system for 4-5 minutes with a constant pressure until the exteriorization of the polymer of the inability to further push the syringe plunger. This is followed by polymer injection at the level of the arterial elements and lastly the biliary elements.

d.Forced polymerization stage: this stage was performed using the high temperature immersion bath method. This method speeds up polymerization bringing in down to 10-15 minutes. We considered this stage completed based on the modified (hardened) consistency of the liver.

e.Corrosion stage: as soon as the part is polymerized the corrosion bath is prepared in the form of a sealed glass vessel, with a capacity of $10000 \mathrm{ml}$ in which $2000-3000 \mathrm{ml}$ of fuming hydrochloric acid are poured. This stage lasts 48 hours.

f.The hydro dissection stage: the corrosion part is carefully handled and passed under a moderate continuous stream of water which favors by hydro dissection the removal of the remaining parenchyma and the excess of hydrochloric acid. Following this stage the piece is left to dry for 24 hours, after which it can be used as a research material.

\section{Results and discussions}

The macroscopic study of the corrosion parts shows that the gallbladder has individual vascular pedicles represented by the cystic artery and the cystic vein, both elements being present in parallel, an aspect almost absent in specialized literature.

The arteries can be single or double - the anterior and posterior branch, a situation in which their origin is almost constantly a collateral of the right branch of the proper hepatic artery. The distribution of the arterial branches frequently consists of two arteries but in some cases only one artery that are normally found on the anterior and posterior aspect of the gallbladder.

We found that in 17 cases $(28.33 \%)$ the anatomical pieces had 2 cystic arteries. In the case of cystic veins, we observed that in 14 cases (23.33\%) the pieces had a single cystic vein, and in 46 cases (76.66\%) the anatomical pieces had multiple cystic veins.

Table 1

ARTERIAL AND VENOUS DISPOSITION OF THE GALLBLADDER VASCULAR SUPPLY

\begin{tabular}{|c|c|c|}
\hline & Single & Multiple \\
\hline Cystic artery & $71.66 \%$ & $28.33 \%$ \\
\hline Cystic vein & $23.33 \%$ & $76.66 \%$ \\
\hline
\end{tabular}

The efferent venous component is represented in particular by a well-differentiated venous plexus, formed around the gallbladder that form one or two branches that drain into the right branch of the portal vein.

In some cases, there is also a second posterior venous component, less accessible but evident by corrosion, which does not materialize as consistent venous branches but is distributed directly to the hepatic parenchyma corresponding to segments S4b and S5. These are distributed directly through the plane of the biliary fossa, transperitoneal, perforating the cholecystic bed. 


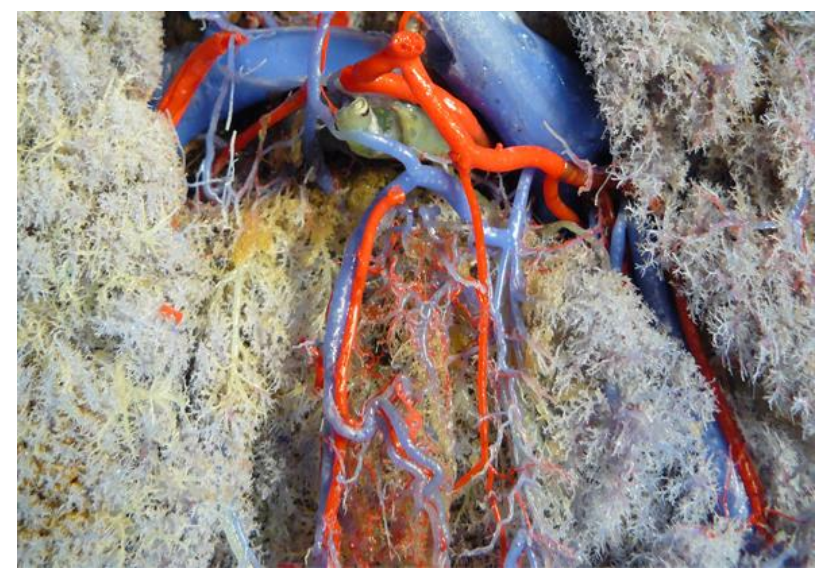

Fig.1. The cystic artery and its two branches. The arterial and portal branches were corroded on this corrosion preparation. Surrounding the gallbladder, the portal component of the adjacent parenchyma is represented by the Glissonian terminal branches in the Disse spaces of segments S5 and S4b

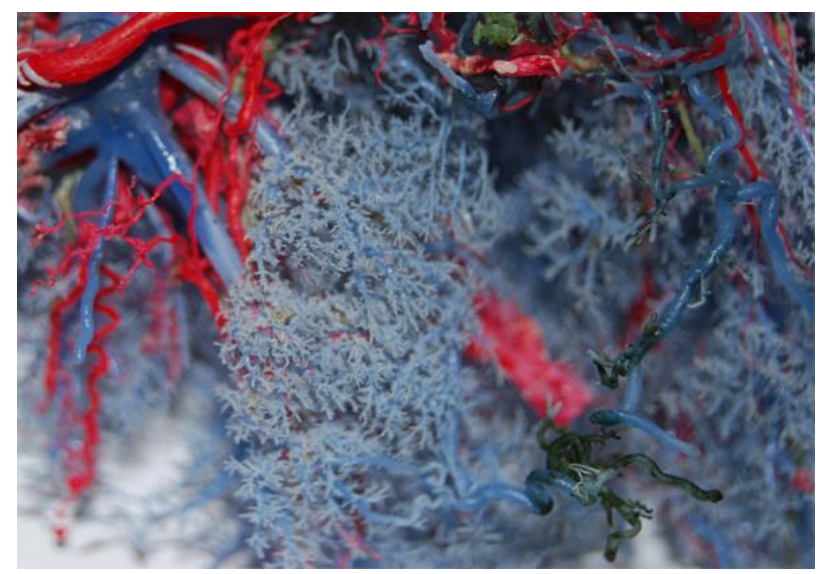

Fig. 2. The space corresponding to the gallbladder fossa - venous components Shown on the right had side is the vascular venous component of the anterior cystic vein showing anastomosis with portal parenchymal branches.

In the lower part of the image, the anastomoses between the cystic vein and the $\mathrm{S} 4 \mathrm{~b}$ branches are observed

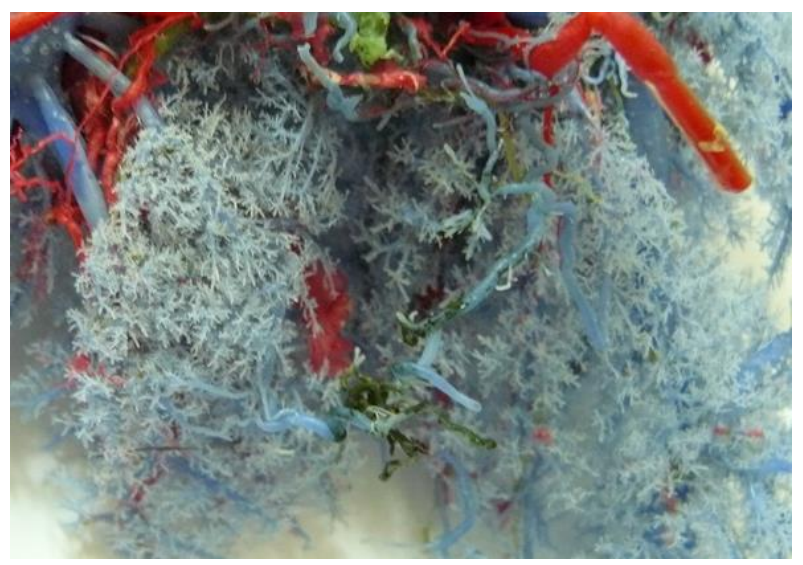

Fig. 3. The venous plexus surrounding the gallbladder. The posterior component of the plexus shows vascular anastomosis with portal branches of the parenchyma of segments S5 and S4b. The arterial component was sacrificed on this specimen for macroscopic highlighting of transperitoneal interportal anastomoses 


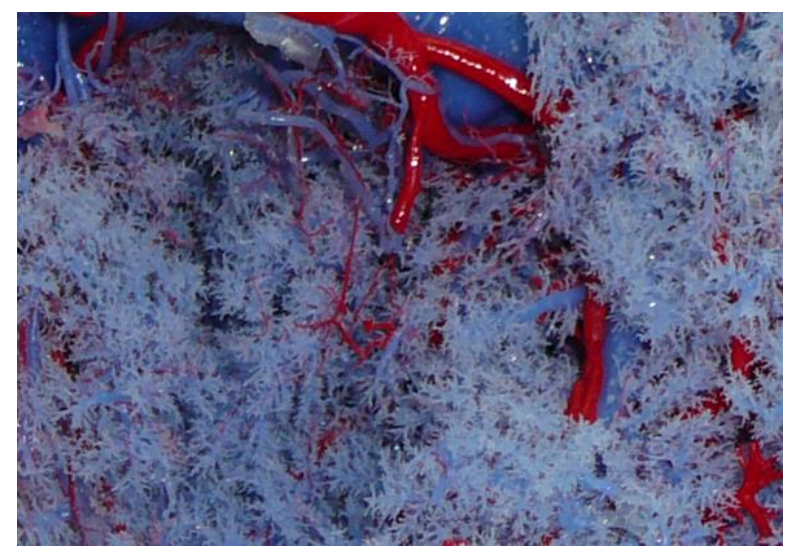

Fig. 4. The gallbladder fossa. The cystic vascular pedicle consisting of artery and vein. The arterial aspect is barely visible. The venous component constitutes a venous plexusthat is anastomosed posteriorly with parenchymal portal branches

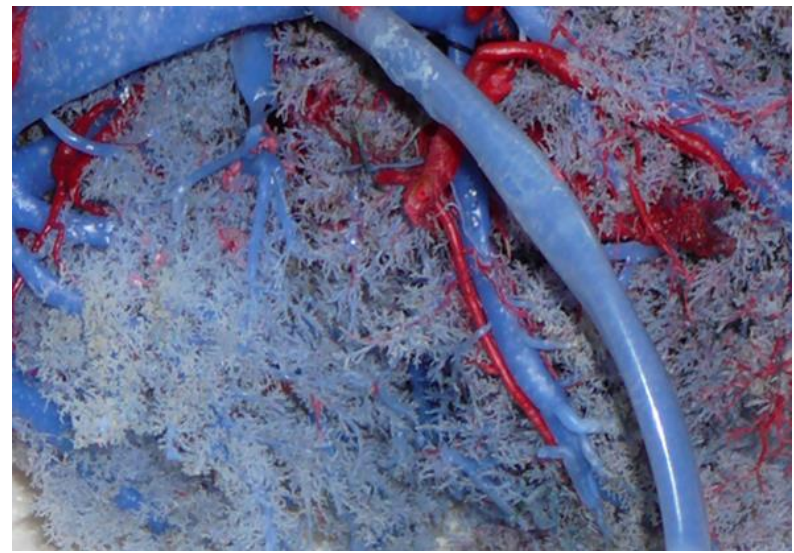

Fig. 5. Gallbladder fossa - the central portion represents the plane of the gallbladder fossa, the presence of the cystic vascular pedicle formed by the arterial branch and the venous branch. The venous plexus surrounding the gallbladder and numerous branches anastomosed posteriorly with the adjacent portal parenchyma can be seen

Based on these observations, it is quite obvious that, there are numerous anastomoses distributed circumferentially and posteriorly, at the level of the cholecystic plaque, transperitoneal between the venous plexus around the gallbladder and the adjacent parenchymatous portal branches.

The most representative pieces are shown next after performing a mesoscopic analysis.

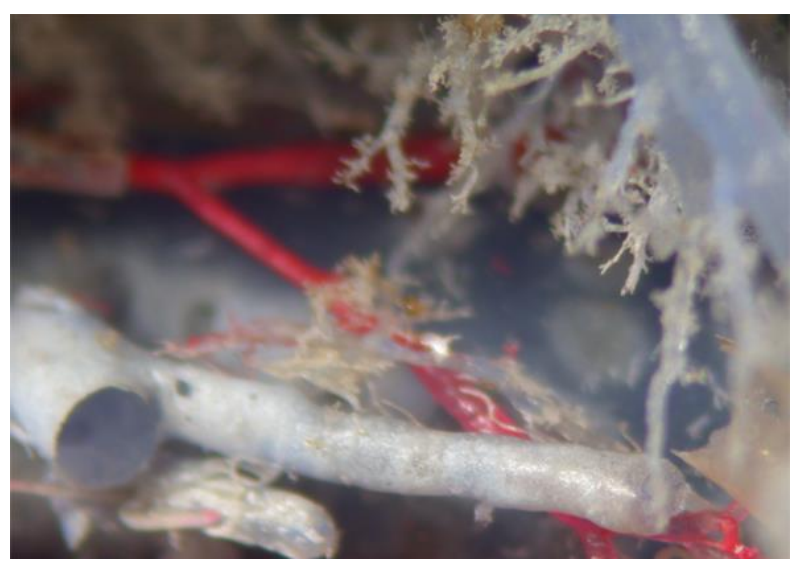

Fig. 6. Gallbladder venous plexus - main view. In the secondary view the parenchymal portal branches are highlighted 


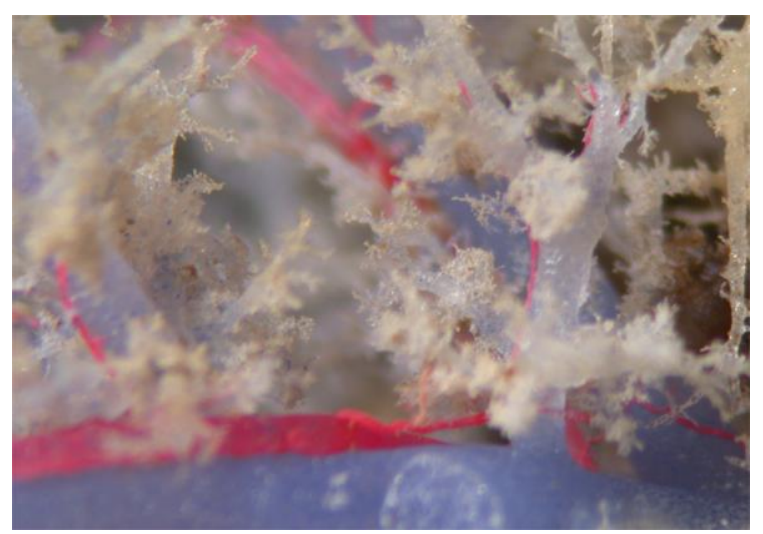

Fig. 7. Posterior distribution of the gallbladder venous plexus towards the adjacent hepatic parenchyma. Transperitoneal drainage at the level of the cholecystic plaque

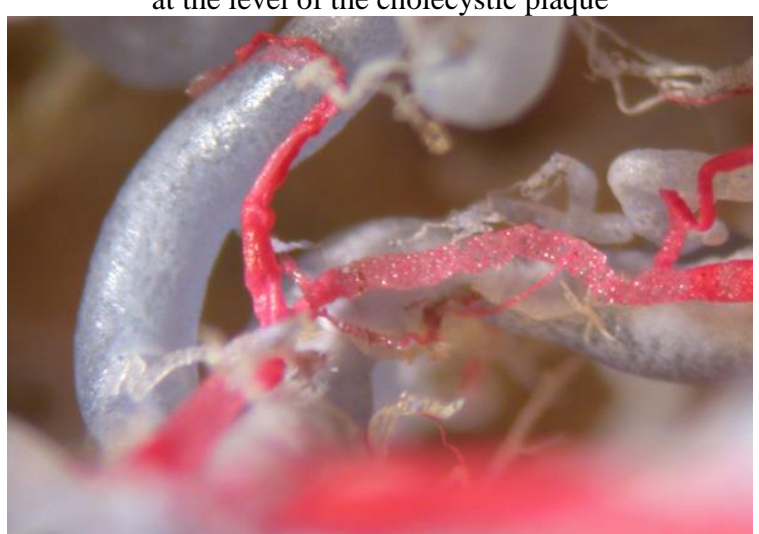

Fig. 8. Cholecystic plexus and anterior cystic vein. Noteworthy is the presence of the arterial component that accompanies the venous component

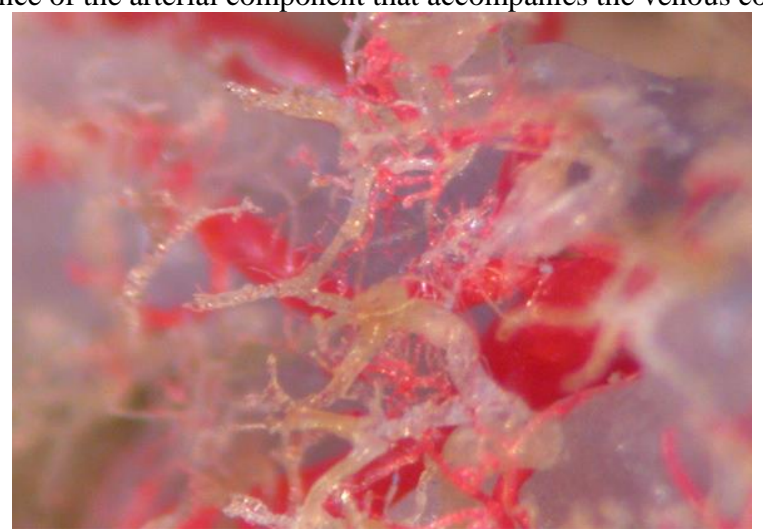

Fig. 9. The two portal venous components - the inferior component that drains the infundibular area, classified as anterior (whitish tint) emptying directly in the portal system, represented by the branches of the pericholecystic plexus and the superior ones classified as posterior (brownish tint) that drain the body and the cholecystic fundus, represented by the transcapsular transperitoneal parenchymal portal branches

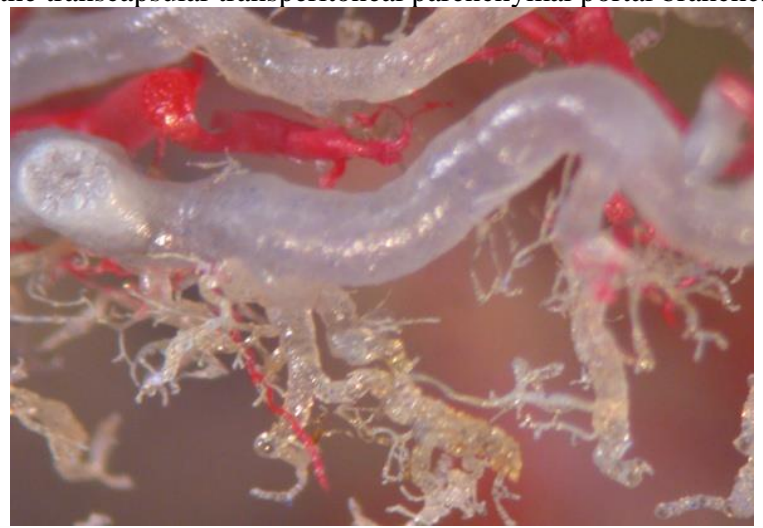

Fig. 10. Pericholecystic anterior component - plexiform in shape and the orientation of branches towards the adjacent parenchyma 


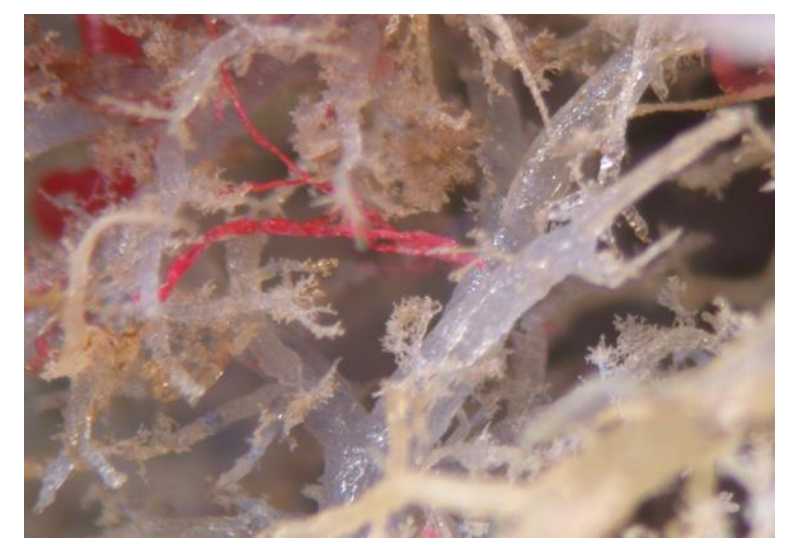

Fig. 10. The two portal venous components and the anastomotic plane between them. The parenchymal branches have a slightly brown tint, probably due to the remaining parenchyma and the bile pigments that influenced the color of methyl methacrylate during polymerization

In addition to the physical existence of these elements, we have demonstrated the existence of interportal communications between the elements of the pericholecystic portal plex and the glissonian portal components at the Kiernan space level.

These anastomoses are found posteriorly to the gallbladder in the bed of the cholecyst, transperitoneal and transcapsular. The macroscopic examination of the corrosion pieces allows the visualization of fine networks colored in bleu used by us for the corrosion of the portal venous system.

Current literature recognizes the presence of these interportal anastomoses, especially in the case of various diseases associated with the portal system and especially in portal thrombosis. In clinical practice, these anastomoses can be evidenced by abdominal ultrasound [5]. There are also authors in the literature who have shown the expansion of cystic veins in patients who had mesocaval shunts, in these cases cystic veins function as collateral drainage pathways [6]. Thus, cholecystic varicose veins are observed in 34\% of patients with extrahepatic portal venous obstruction [7-9].

Most commonly, venous drainage of the ventral surface of the gallbladder is done through a single cystic vein, while its dorsal aspect is drained through one or two veins that join with the veins that drain the main biliary tract. Both venous systems drain into the right branch or flow directly into the portal vein [10].

Most commonly, the cystic veins also drain the bed of the gallbladder. The parabiliary venous system found in the hepatoduodenal ligament drains on the anterior face of the portal vein. This system collects blood from the level of the pancreatic cephalic region, the distal part of the stomach and the biliary system in the vicinity of the cholecyst. These two systems drain into the portal vein but occasionally they can drain directly into the liver adjacent to the portal vein resulting in isolated perfusion $[11,12]$.

Song et all in 2000 report that biliary, cystic, pericholedochal, left and right gastric veins are the most commonly seen collaterals in the case of cavernous transformation of the portal vein. Biliary veins appear as visual markers in the case of portal vein cavernoma in 83-94\% of cases and $0 \%$ in the case of lack of cavernoma. [13]

All the studies presented certify the presence of cystic varices and show their pathognomonic association with portal thrombosis or portal cavernoma. The fact that the venous blood flow in the inferior vena cava increases significantly in the extra hilar portal cavernoma is a further proof of the existence of indirect communications between the portal vein and the inferior vena cava, which are none other than the interportal anastomoses at the level of the hilum plate.

Based on angiographic studies, it was demonstrated that the cystic venous flow infuses segments 4 and 5, 6 and the right hepatic vein [14-16]. It has also been shown that cholecystic venous blood very frequently enters the peripheral portal system of segment 5 (96\%) and segment 4 (93\%). In an imaging study that followed the development of hepatic metastases in gallbladder carcinoma, it was shown that the metastatic hepatic territories are correlated with the cystic venous drainage areas, and the parenchymal venous drainage areas can be considered as markers of some areas with the potential to develop liver metastases in cholecystic carcinoma [19].

\section{Conclusions}

The macroscopic and mesoscopic observational study of the corrosion parts demonstrates the presence in most cases of a true pedicle, a cystic arterio-venous plexus and a pericholecystic portal venous plexus, present both at the level of the anterior face, visceral but especially at the level of the posterior cleavage layer between the gallbladder and Glisson's capsule.

In addition to the physical existence of these elements, we also noticed the presence of interportal communications between the elements of the pericholecystic portal plex and the glissonian portal components. These anastomoses are performed at the level of the cholecystic, transperitoneal and transcapsular plate. We injected two shades of color bleu and the abundant presence of bleu colored elements (dye used for the portal vein) certify their origin at the level of the segmentar portal venous system. 


\section{References}

1.SARELI M., ZENDEL A., NISSAN A., ZIPPEL D., Am. Surg., 85,2019,nr.1,p.71-75

2.HĂLMACIU I., SUCIU BA., TRÎMBIȚAȘ C., VUNVULEA V., IVĂNESCU A., CLIPA A., ADĂSCĂLIȚEI P., BRÎNZANIUC K., FODOR

D., Mat. Plast., 55, no. 3, 2018, p.414-418

3.SUCIU BA., HĂLMACIU I, FODOR D., TRÂMBIȚAȘ C., GODJA D., CLIPA A., NICOLESCU C., BRÎNZANIUC K., VUNVULEA V., Mat. Plast., 55, no. 3, 2018, p.380-384

4.SUCIU BA., HĂLMACIU I., VUNVULEA V., BRINZANIUC K., Eur. J. Cardiothorac. Surg., 53,2018,nr.4,p.895-896

5.MARCHALL GJ., VAN HOLSBEECK M., TSHIBWABWA N., GODDEERIJ PG., FEVERY J., OYEN RH., ADISOEJOSO B., BAERT AL., VAN STEENBERGEN W., Radiology 154,1985;NR.1,p.187-189

6.CHARNSANGAVEJ C., THORNHILL B., CHUANG V., BERSTEIN RG., Cardiovasc. Intervent. Radiol. 7,1984,nr.5;p.247-250

7.CHAWLA A., DEWAN R., SARIN SK., Am. J. Gastroenterol. 90,1995,nr.11,p.2011-2014.

8.BUD V., SUCIU BA., BUTIURCA V., BRÎNZANIUC K., COPOTOIU R., COPOTOIU C., SIN A., Rom. J. Morphol. Embryol., 54,2013, nr.1,p.115-119.

9.SUCIU BA., PAP Z., DENES L., BRÎNZANIUC K., COPOTOIU C., PAVAI Z., Rom. J. Morphol. Embryol., 57,2016,nr.2,p.495-500.

10.KADIR S., Atlas of normal and variant angiographic anatomy, Philadelphia: W.B. Saunders Co: 1991: p.97-386

11.MACHADO MM., FERREIRA RA., DA MOPA et al., Radiol. Bras. 39, 2006; nr.2, p.151-155.

12.MUREȘAN M., MUREȘAN S., BARA T., NEAGOE R., SALA D., SUCIU B., Cir. Cir., 84,2016,nr.5,p.376-383

13.SONG B., PENGQUI M., OUDKERK M., XIANPING Z., YINGHUI G., JUN X., WEIXIA C., XIAN C., Abdom. Imaging 25,2000,nr.4,p.385393.

14.KUMAOKA H., KIKUYAMA M., KITANAKA H., KAYAHARA T., HORIO Y., MATSUBAYASI Y., TOBE T., Nippon. Shokakibyo. Gakkai. Zasshi., 95,1998,nr.5,p.419-423.

15.YOSHIMITSU K., HONDA H., KANEKO K., KUROIWA T., IRIE H., CHIJIIWA K., TAKENAKA K., MASUDA K., Am. J. Roentgenol. 169,1997, nr.2, p.505-510

16.CHIRIAC A., BRZEZINSKI P., STOLNICU S., PODOLEANU C., MOLDOVAN C., MOLNAR C., TARANU T., J. Dermatolog. Treat., 27,2016,nr.2,p.110-113

17.GURZU S., JUNG I., COMSULEA M., KADAR Z., AZAMFIREI L., MOLNAR C., Diagn. Pathol., 2013 Sep 16;8:150, doi: 10.1186/17461596-8-150.

18.UNNO M., SUZUKI M., KATAYOSE Y., TAKEUCHI H., RIKIYAMA T., MATSUNO S., Nihon. Geka. Gakkai. Zasshi., 103,2002,nr.8,p.543-548

19.YOSHIMITSU K., HONDA H., KUROIWA T., IRIR H., AIBE H., TAJIMA T., CHIJIIWA K., SHIMADA M., MASUDA K., Cancer 92,2001,nr.2,p.340-348

Manuscript received: 05.12 .2019 